\title{
Commentary
}

\section{Marginal mandibular nerve - Interpolation from anatomy: A flaw?}

\section{Sasanka Sekhar Chatterjee}

Department of Plastic Surgery, IPGME \& R, Kolkata, India

Address for correspondence: Dr. Sasanka Sekhar Chatterjee, Department of Plastic Surgery, IPGME \& R, Kolkata, India

he authors have undertaken an important study from the plastic surgeon's point of view. The marginal mandibular nerve is at times injured temporarily or permanently by trauma, tumour and surgery. ${ }^{[1]}$ It is located in an area that is frequently handled by members of many surgical specialties, like plastic and general surgeons, 
faciomaxillary and oncosurgeons and otolaryngologists. Hence, the importance of anatomy of this structure and literature is full of studies on dissection of this nerve. ${ }^{[2,3]}$ Among all the branches of the facial nerve, the recovery from this nerve is the poorest as interbranch communications are the least. ${ }^{[4]}$

Clinical experiences with over 2,000 parotidectomies show that each facial nerve has its own complex and varied anatomic pattern. ${ }^{[5]}$ The mandibular branch is delicate and connects with the other branches in only $10-15 \%$ of the cases, and nearly always lies deep to the platysma. But, development of platysma is variable and, in some old individuals, it is so thin and atrophic that it is difficult to identify. The other anatomic point of importance is that although the nerve is superficial in its course, its branches always enter the innervated muscles deeply. ${ }^{[4]}$

The authors have found an average distance of the loop of the marginal mandibular nerve to be $1.2 \mathrm{~cm}$ from the inferior border of the mandible and concluded, on the basis of their and other studies, that incisions should be made $1.6 \mathrm{~cm}$ below the inferior border of the mandible to avoid damage to this nerve. It is well known by the surgeons that in some individuals with lax and atrophic tissues, it may even be 3-4 cm below the lower border of the mandible. ${ }^{[4]}$ Extension of the neck on the operation table draws the nerve even lower. ${ }^{[6]}$ This is important as people with laxity and atrophy of facial tissue frequently come for surgical rejuvenation of the face.

There are two very important differences between cadaveric study and patients in operation theatres.

\section{THE POSITION OF THE HEAD}

While the authors have made this study in cadavers, it is not clear whether they tried to mimic the position of the heads as it is held during operations in the theatres. This is important from the surgeon's point of view as he may often alter the position of the head during dissection. This has not been mentioned anywhere in the study.

\section{FRESHNESS OF THE CADAVER}

From the images, it appears that the cadavers dissected were not fresh. Obviously, the measurements in such specimens will not correlate with living bodies. Contribution from the authors would have been more worthwhile if this study was performed in fresh cadavers so that the position of the head could be extended as during the operations. Perhaps some new data could have come to the fore to prevent a common complication during surgery in the submandibular region.

\section{REFERENCES}

1. Zuker MR, Manktelow RT, Hussain G. Facial paralysis. $2^{\text {nd }}$ ed. Plastic Surgery In: Mathes SJ, editor. W. B. Saunders Company: Philadelphia; 2006. p. 880.

2. Davis RA, Anson BJ, Budinger JM, Kurth LR. Surgical anatomy of the facial nerve and the parotid gland based upon a study of 350 cervicofacial halves. Surg Gynecol Obstet 1956;102:385412.

3. Miehlke A, Stennert E, Chilla R. New aspects in facial nerve surgery. Clin Plast Surg 1979;6:451-70.

4. Baker DC. Facial Paralysis. 1st edition. Plastic Surgery In: McCarthy JG, editor. W. B. Saunders Company: Philadelphia 1990. p. 2241-3.

5. Baker DC, Conley J. Avoiding facial nerve injuries in rhytidectomy: Anatomical variations and pitfalls. Plast Reconstr Surg 1979;64:781-95.

6. Freeman BS. Facial palsy. $2^{\text {nd }} E d$. Reconstructive Plastic Surgery In: Converse JM, editor. W. B. Saunders Company: Philadelphia: 1977. p. 1774 